\title{
La vecindad en la ciudad de Toledo hacia 1400
}

\author{
Pilar Morollón Hernández \\ Catedrática de Historia del IES Sefarad de Toledo ${ }^{1}$
}

\begin{abstract}
RESUMEN ABSTRACT
Aproximación a la realidad social de los vecinos de la ciudad de Toledo en la segunda mitad del siglo xiv a través de

sus características definitorias, sus privilegios y responsabilidades, tomando como fuente fundamental las Ordenanzas Antiguas de la ciudad de 1400.

A brief description of Toledo's neighbourhood social reality during the second half of the XIV century, going through their distinctive features, their privileges and responsabilities, taking city's Ancient By-Laws as the main source.
\end{abstract}

\section{PALABRAS CLAVE}

Vecino, morador, residencia, pecha, caballeros, hombres buenos, común, ordenanzas municipales, colación, fieles de las colaciones.

\section{KEY WORDS}

Neighbour, dweller, residence, tax, knights, honest men, commo goods, by-laws, parish, parishioners.

El concepto de vecindad en Toledo fue peculiar hasta la Baja Edad Media, porque fue la primera gran ciudad musulmana adquirida mediante pacto por el monarca Alfonso VI en 1085 y, a raíz de esa incorporación al reino castellano, sus habitantes se rigieron por seis legislaciones diferentes, según su procedencia, religión o estado. Así Alfonso VI otorgó el Fuero a los Castellanos en fecha imprecisa, pero

- Se utilizan las siguientes abreviaturas AHDE (Anuario de Historia del Derecho Español), IPIET (Instituto Provincial de Investigación y Estudios Toledanos), AHN (Archivo Histórico Nacional), UCLM (Universidad de Castilla-La Mancha), O.T.4 (Texto de las Ordenanzas Antiguas de Toledo utilizado para este trabajo. Archivo Municipal de Toledo, Archivo Secreto, Alacena $2^{a}$, legajo $6^{\circ}$, documento $n^{\circ} 4$ ). 
antes del 19 de marzo de 1101 en que concedió el Fuero a los Mozárabes, la situación de los musulmanes quedó regulada por el pacto de capitulación, y los judios tendrian una cierta autonomía, según sus preceptos. A esta situación, que fragmentaba jurídicamente la población toledana, se añadió el Fuero de los Francos, dado por Alfonso VII en Burgos el 24 de abril de 1136, y la confirmación de los fueros que el clero habia tenido en tiempos de Alfonso VI, realizada el 18 de junio de $1136^{2}$.

De este modo, no se puede concebir a los habitantes toledanos formando una comunidad solidaria de vecinos, sino más bien una suma de grupos con particularismos que restan más que suman. $Y$ esto, aunque el fuero de los Mozárabes utilice por vez primera la palabra vecino y en él se diga «Hoc autem mando, ut populator vendat ad populatorem et vicinus ad vicinus", contraponiendo el vecino (mozárabe) al poblador (castellano o franco), si bien esta cláusula restrictiva es obviada en la mejora del texto foral de 1166 y parece más un intento de salvaguardar los derechos de la comunidad mozárabe que de establecer diferencias entre ambas categorias de habitantes ${ }^{3}$.

\section{ESTABLECIMIENTO DE LA VECINDAD EN TOLEDO}

Será a partir del siglo XIII, como en el resto de la Península, cuando la ciudad vaya pasando de la foralidad a la municipalidad y el autogobierno. Resguardada por la jurisdicción real, organiza su régimen concejil basado en los privilegios que conceden a la ciudad los sucesivos soberanos, y dotándose de ordenanzas municipales, elaboradas por el propio concejo, que regulan casi todos los aspectos de la vida urbana, entre ellos el de la vecindad ${ }^{4}$.

Las Ordenanzas Municipales más antiguas de Toledo fueron redactadas en 1398, y autorizadas y legalizadas públicamente por el concejo el 12 de julio de $1400^{5}$, siendo alcaldes Pero López de Ayala ${ }^{6}$, que fue el impulsor de la recopilación legislativa, y Juan Carrillo. En ellas se recoge la legislación concejil anterior, y también se legisla ex novo, respondiendo a las nuevas necesidades de la población. Las ordenanzas no solamente obligan al vecino sino a todos los habitantes

2 Garcia Gallo, A: "Los Fueros de Toledo. "AHDE LXV (1975), pp. 341-488

3 MARTINEZ LlORENTE. F: “El régimen jurídico de la vecindad medieval y las novedades del Ius Comune". Las Sociedades urbanas en la España Medieval. XXIX Semana de Estudios Medievales, Estella 15-19 de julio de 2002, pp. 51-80.

"SARASa SANCHEZ, E: "Concejos y ciudades medievales en el reino de Aragón". Concejos y Ciudades en la Edad Media Hispánica. Madrid, Fundación Sánchez Albornoz, 1990, pp. 73-106.

5 Las Ordenanzas Antiguas de Toledo se recogen en sendos manuscritos conservados en el llamado Archivo Secreto del Archivo Municipal de Toledo, con las signaturas: Alacena $2^{a}$, legajo $6^{\circ} n^{\circ} 5$, que es una copia sin autorizar de 1398 , y la copia correspondiente a Alacena $2^{a}$, legajo $6^{\circ}, n^{\circ} 4$ que es la copia legalizada de 1400, que es la que utilizaremos en este estudio. (En adelante O.T.4). Las copias son del siglo $x \vee$ y permanecen inéditas.

6 Pedro López de Ayala, hijo del Cancilier e intelectual del mismo nombre, sucedió a su padre como Alcalde Mayor de Toledo en 11 de mayo de 1394, cargo que ocupó hasta ef 13 de abril de 1441 , fecha en que delegó en su hijo, el primer conde de Fuensalida. 
tanto de la ciudad, ya sean vecinos, moradores o transeúntes, como del término, incluidos los Montes y Extremos de Toledo, Guadiana aquende y allende, sobre los que el concejo extendía su jurisdicción. En ellas se recogen explícitamente, a lo largo de sus capitulos, parte de los derechos que tienen los vecinos, y las condiciones para adquirir la vecindad.

\section{¿Quién es vecino en el Toledo del siglo XIV?}

Según Carmen Carlé, serían tres los elementos constitutivos del concepto de vecindad: la propiedad, la residencia y la pecha? Haremos precisiones a ello en el Toledo bajomedieval.

La primera cualidad del vencindaje es documentalmente verificable. Solamente es vecino quien es propietario de bienes inmuebles en la ciudad o de bienes raíces en su término ${ }^{8}$. Aunque no todos los propietarios son vecinos. Una de las condiciones para ser aceptado como nuevo vecino era tener "casas propias de suyo" en Toledo ${ }^{9}$, como se lee también en el capítulo XXVI en el que habla de "los vezinos que nuevamente vienen a Toledo: Otrosi, que los que se fizieron o fizieren vezinos de Toledo nuevamente comprando casas e heredat, que non los hayan por vezinos fasta que pidan a Toledo la vezindat ${ }^{10}$ ".

Por tanto, son vecinos aquellos que, habiendo nacido en la ciudad o siendo hijos de vecinos, tienen propiedades en la misma, como se sobrentiende cuando se dice "que los que vengan a hacer vecindad, que non sean naturales de Toledo (...) " o los que no tienen casa ni viña "nin la ovieron sus padres»" $"$ También pueden llegar a ser vecinos los propietarios foráneos o moradores que contraen matrimonio con una hija de un vecino ${ }^{12}$ o solicitan dicha condición al Concejo y le es concedida por la autoridad de éste.

La segunda cualidad imprescindible para mantener la vecindad es la residencia. Se ordena "tener en la dicha çibdat casas propias suyas de su morada, morando en la çibdat en ellas con su muger e con la su mayor casa poblada la mayor parte del año continuadamente. E quando estos tales ovieren de ir a otra parte fuera de la çibdat, que dexen la casa poblada con toda su fazienda, e non pueda tener en las dichas casas alquilador alguno" ${ }^{13}$, y se repite en otros capítulos. Hasta el siglo Xv se exigen cinco años de residencia para poder ser considerados vecinos

\footnotetext{
CARle. M. C: "El Concejo medieval castellano leonés". Buenos Aires, Instituto de Historia. 1968 p. 85.

* En O.T.4, capítulo V, ley X, folio XVIr, se especifica que "qualquier o qualesquier que en Toledo morare o moraren de aqui adelante, que no han de suyo casas ni viñas ni las ovieron sus padres de suyo en Toledo, non metan en Toledo su vino nin sus uvas para fazer vino, derecho privativo de los vecinos.

Y O.T.4, capitulo $V$, ley XIII, folio XVIIIr.

10 O.T.4, capitulo $X X V I$, folio $L X V$.

11 O.T.4, capitulo $V$, leyes IX y X, folio XVIr

12 O.T.4, capitulo V, ley XIII, folio XVIIV.

15 OT.4, capitulo $V$, ley XIIII, folio XVIIIV.
} 
de la ciudad si se es originario del término, como se deduce de la ordenanza $L X I$ sobre los que «nuevamente de çinco años acá se vinieron de sus aldeas a se avezindar a Toledo maliziosamente» en la que se exige que, los habitantes que no lleven cinco años viviendo en la ciudad, vuelvan «(...)en ora buena a morar e bevir a los logares a aldeas donde vinieron e onde tienen sus faziendas e casas e heredades e fagan alli su morada. Por que los dichos logares e aldeas se pueblen e non se yermen nin despueblen por su ocasión e pechen e sirvan al rey según lo siempre ante desto fizieron (...) ${ }^{14}$. A mediados de ese siglo ya serán necesarios 10 años para adquirir la vecindad ${ }^{15}$.

Sin embargo, el tercer requisito que apuntaba Carmen Carlé, la pecha, no es imprescindible en Toledo al estar exentos de pagar impuestos los principales vecinos de las ciudades medievales: los caballeros villanos, escuderos, dueñas y doncellas. Todos ellos estaban eximidos de tributación por las heredades que poseian en el término, por privilegio concedido por Alfonso VIII el 30 de septiembre de 1182; Enrique I exime de alosores a los caballeros de Toledo y de las aldeas de su término el 3 de febrero de 1217; Alfonso $X$ exime a los caballeros, dueñas, escuderos e hidalgos, del pago de moneda el 26 de enero de 1259; Fernando IV exime del pago de la luctosa a la Orden del Temple a los caballeros y escuderos de Toledo el 2 de abril de 1308; todos ellos confirmados por los monarcas posteriores ${ }^{16}$.

Todos los vecinos, tanto caballeros como hombres buenos o gentes del común, fueron los beneficiados de otros privilegios reales, destacando la dispensa en el pago de impuestos: exención de portazgo y aloxor concedido por Alfonso VII a todos los habitantes cristianos el 18 de marzo e 1137; exención de posadas concedida por Alfonso $X$ el 6 de febrero de 1260; la exención del pago de moneda concedida por Sancho IV el 30 de diciembre de 1289; exención de pechar por los algos que tuviesen en cualquier lugar del reino, y que no pecharan los vasallos y apaniaguados de los vecinos de Toledo excepto de moneda forera, concedidos por Fernando IV el 22 de marzo de 1303; exención del portazgo en todo el reino para sus ganados y mercancías y que pudiesen comprar libremente casas y heredamientos donde quisieren, concedidos por Alfonso XI el 28 de octubre de $1313^{17}$.

En virtud de todo ello, los vecinos de Toledo no pagaban impuestos ni concejiles ni una parte de los reales, incluido el almojarifazgo sobre el vino que llevaban a vender fuera de la ciudad ${ }^{18}$, ni la alcabala sobre las rentas en especie sobre las heredades y huertas ${ }^{19}$.

${ }^{14}$ OT.4, capitulo LXI, folio CXXVIIV

15 IZQUiERdo Benito, R: “Un espacio desordenado: Toledo a fines de la Edad Media". Toledo, UCLM-Diputación Provincial, 1996, p. 42.

16 Izoulerdo Benito, R: "Privilegios Reales otorgados a Toledo durante la Edad Media" (1101. 1494).Toledo, IPIET, 1990.

17 IZQUIERDO BENITO, R: «Un espacio desordenado. ..» p. 40

${ }_{14}$ Segun sentencia del Concejo de 1401 recogida en O.T.4, capitulo LXXXI, folio CXXXIX y sig.

19 O.T.4, capitulo XLI, folio LXXXIIIIV. 
Abundando en las cualidades imprescindibles para la vecindad, son vecinos los hombres cabeza de familia. Las mujeres, aunque sean naturales de la ciudad, incluso de varias generaciones, son vecinas de pleno derecho cuando son cabeza de familia, situación que llega con la viudedad o la emancipación, o cuando son esposas de un vecino. Pero pueden transmitir la vecindad a través del matrimonio, siendo esta una de las posibilidades para un morador o un forastero de llegar a conseguir formar parte de la comunidad de vecinos ${ }^{20}$.

En sintesis, es vecino de Toledo a fines del siglo xIV todo aquel hombre o mujer cabeza de familia o emancipados, que son naturales de la ciudad o han adquirido carta de vecindad, que poseen tierras en su término y casa intramuros poblada todo el año, donde tienen su domicilio habitual, entendiendo por tal «donde cada cual constituyó sus lares y el conjunto de sus cosas y su fortuna, y de donde no haya de alejarse otra vez, si nada obliga, y de donde partió se considera que está de viaje, y cuando volvió, que dejó ya de viajar (... $){ }^{21}$ que especificaba el Derecho Común.

Todos los vecinos, tanto los naturales de la ciudad como los nuevos vecinos, estaban obligados a tener una carta de vecindad, librada por el concejo, sellada con los sellos oficiales de la ciudad y firmada por el escribano de Toledo, ya que es potestad del concejo el privilegio de concesión de la vecindad ${ }^{22}$. En el caso que no tuvieran dicho documento, los fieles de las colaciones ${ }^{23}$ deberian amonestarlos para que la recogieran en un plazo de 20 días, y si no lo hicieran, perderian el estatuto de vecino "que los non ayan por vezinos de Toledo nin gozen de las libertades e franquezas de que los vezinos de Toledo deben gozars ${ }^{24}$.

Como vemos, la vecindad no es estatus vitalicio ni hereditario, puede perderse en el caso de no detentar la carta de vecindad, pero también si se traslada el domicilio habitual a otro lugar tanto del término como fuera de él, o cuando no se mantenga la casa familiar abierta y poblada la mayor parte del año. Se podía dar el caso de algún vecino de Toledo que era morador en otro lugar sin perder la vecindad, pero no era lo común ${ }^{25}$.

Para acercarnos más a la realidad social que encierra la vecindad, hemos consultado los repertorios documentales de los archivos de los monasterios de San Clemente el Real ${ }^{26}$ y Santo Domingo el Real de Toledo ${ }^{27}$, de la segunda mitad del

20 O.T.4, capítulo V, ley XIII, folio XVIIV

2 CODEX, X, 39, 7, citado por MARTinez LloRente, F. Op. cit. p. 73.

"Asenjo Gonzalez. M: "Segovia. La ciudad y su tierra a fines del medievo". Segovia, Diputación Provincial, 1988.

$2: 3$ La colación es la circunscripción municipal de agrupamiento de vecinos, donde mejor se plasman las solidaridades vecinales. En ellas, los vecinos eligen anualmente a sus representantes, llamados fieles, que son nexo de unión entre los vecinos y el concejo.

4 O.T.4, ley XXVI, folio LXIr.

AHN. Sección Clero. Carpeta 3075 , doc. n. ${ }^{\circ} 8$ de 1395. Carta de venta por la que Juan Altonso de la Cadena, vecino de Toledo y morador en Casarrubios del Monte vende una casa en el Arrabal de Toledo.

26 ToRroja MEndez, C: "Catálogo del Archivo del Monasterio de San Clemente de Toledo (11411900). Toledo, IPIET, 1973

Archivo del Convento de Santo Domingo el Real de Toledo www. dominicos.org/archivotoledo y Archivo Histórico Nacional. Sección Clero. Carpetas 3074, 3075, 3076, 3077 y 3078. 
siglo XIV, comprobando que en 78 documentos de los 126 consultados, aparecen nombrados vecinos y en 48 solamente moradores.

Según la documentación, son vecinos los grandes personajes de la oligarquía local que, en muchos casos, tienen proyección social más allá de la ciudad, en las cercanías del poder real. Se recogen un total de 11 de ellos, 8 viudas y 3 hijas emancipadas de esas familias y linajes (22 personajes de este grupo social) entre los que destacan Luis Méndez de Sotomayor, Alfonso Tenorio adelantado de Cazorla, Pero López de las Ruelas, Gudiel Alonso Cervatos, Tel García hijo de García Sánchez de Meneses, Juan Núñez de Aguilar, Inés de Ayala viuda de Diego Gómez alcalde mayor de Toledo, Teresa de Ayala viuda de Juan Núñez de Aguilar, Sancha de Ayala viuda de Mosen Manuel de Villa Román, Urraca de Ribera viuda de Juan Díaz de Rocafull, Constanza viuda de Pero Díaz Palomeque, Inés Alfonso Cervatos, Juana García viuda de Fernando Garcia alguacil mayor, María Alfonso viuda de Juan García Laso, alguacil mayor....Ellos realizan ventas de propiedades urbanas y rurales, las arriendan, las dan a censo, hacen donaciones a los conventos, y dictan testamentos. La mayoría de las viudas de este grupo social están recluidas en conventos, en algunos casos sin participar completamente de la vida monástica, en otros siendo incluso prioras, sin perder la vecindad.

Los clérigos, tanto regulares como seculares también participan de la vecindad y sus derechos. Aparecen como vecinos administrando su patrimonio particular Ruy Fernández doctor en decretos y canónigo de Toledo, fray Gil fraile de San Francisco ${ }^{28}$, o el preste Antonio natural de Roma y vecino de la ciudad ${ }^{29}$.

Pero la mayoría de vecinos debían formar parte de los llamados hombres buenos, y de los habitantes del común. Se muestran en la documentación personajes propiamente urbanos, así escribanos, abogados, subarrendadores de alcabalas, criados de personajes importantes (5 en total); artesanos de diversos oficios como entalladores, tejedores de seda, tundidores, traperos, pergamineros, vaineros, albañiles (10), un carretero dos hortelanos. Además de otros muchos, matrimonios, hombres o viudas e hijas emancipadas (36) de los que desconocemos estatus social o profesional y que son propietarios sobre todo de casas o que toman a censo casas o tierras. Es de resaltar que en un documento aparecen un matrimonio moro especificado como vecino.

De un total de 45 personajes de los que conocemos su estatus social, el $55,5 \%$ forman parte del grupo de caballeros, incluyendo en él a los tres clérigos del que sin duda procedian; $13,3 \%$ eran burgueses del sector terciario; un $22,2 \%$ eran artesanos y sólo $8,9 \%$ pertenecian a las clases populares.

Las transacciones recogidas en los documentos son esencialmente compraventas de propiedades urbanas y rústicas ( 33 documentos), arrendamientos de bienes urbanos y rústicos ( 13 ocasiones), donación a monasterios y criados, testamentos, un cambio de propiedades y la compra de un moro cautivo. Mayorita-

Torroja Mendez, Op. cit. documentos n. 453 (1394) y 459 (1394).

29 AHN, sección Clero, carpeta 3074, doc. n. 11 y 12 (1391). 
riamente operaciones relacionadas con su cualidad de propietarios en la ciudad y su término.

En cuanto a los 49 documentos en los que se especifica la única cualidad de morador, no se constata el origen social en 28 ; son caballeros, viudas e hijas de caballeros 7 de los citados, normalmente vecinos de otros lugares pero residentes ocasionalmente en Toledo, o habitantes de los conventos de la ciudad sin ser originarias de ésta; 3 pertenecian a la burguesía de servicios (escribano, mayordomo, criado de alto personaje), 1 artesano, 1 molinero, 7 judíos y 5 moros. La escasez de datos de los moradores ya es significativa, sin duda porque en su mayoría no eran propietarios.

Las escrituras recogen mayoritariamente compraventas de propiedades tanto urbanas como rústicas ( 25 entradas) pero es significativa la mención en 13 ocasiones de toma en arrendamiento o censo de propiedades rústicas y urbanas, 3 alusiones a deudas o deudores y solamente un testamento, lo que nos indica el posible origen social humilde de la mayoria de los moradores que son sujetos de una documentación ya de por sí centrada en contratos propietarios.

\section{DERECHOS DE LOS VECINOS}

Desde el punto de vista económico, el derecho más importante de los vecinos era el aprovechamiento de los bienes comunales situados tanto en la tierra o término que rodeaba la ciudad, como en los Montes de Toledo y los márgenes del Guadiana, territorio adquirido por el concejo al rey Fernando III en 1246, por $45.000 \mathrm{mrs}$. La utilización de extensos pastos de invernada para el ganado ovino y la montanera de bellota fueron recursos abundantes en las dehesas extremeñas, mientras que en los Montes de Toledo fueron habituales la instalación de colmenas, la caza y pesca, el carboneo, el abastecimiento de madera y la extracción de otras materias primas y productos; actividades que enriquecieron a no pocos vecinos ciudadanos, que llegaron a apropiarse de los bienes comunales mediante roturaciones y adehesamientos, que trataban de prohibirse con desigual éxito por las ordenanzas municipales.

Políticamente, el derecho esencial de los vecinos es la participación en el concejo, mediante la asistencia a las asambleas vecinales que se celebraban a las puertas de la catedral, antes de que éstas se conviertan en restrictivas, y a través de la intervención en sus colaciones, en las que se elegian a sus fieles o representantes. También estaba reservado a los vecinos el ejercicio de los cargos públicos y oficios concejiles como las escribanías públicas, así los aprendices de escribanos públicos tienen que ser "vezinos e fijos de vezinos, naturales de Toledo" ${ }^{30}$.

Además, las ordenanzas municipales recogen minuciosamente otros derechos vecinales que abarcaban numerosos aspectos de la vida económica, sobre todo comercial, o jurídica.

30 O.T.4, capitulo LVIII, ley X, folio CXIIIIr. 
Con respecto a los derechos comerciales, podían vender trigo para hacer pan en sus propios alholíes, o almacenes particulares, según era costumbre y no en el mesón del grano, lugar de venta obligatoria para los no vecinos ${ }^{31}$. Son numerosas las prerrogativas vecinales referentes a la comercialización del vino, principal recurso de los propietarios urbanos, muy protegido por las autoridades municipales. Los vecinos podían vender en Toledo el vino que producian en sus viñas y el que compraban en el término o fuera de él salvo el vino producido en Ocaña, Dos Barrios, Illescas y otras villas con jurisdicción propia, y vender vino de viñas situadas en Yepes o Cabañas de Yepes si tenian plantadas las vides desde más de diez años ${ }^{32}$. Los registradores encargados de controlar el vino de entrada, tenían obligación de registrárselo y darles el correspondiente albarán de autorización de entrada del producto intramuros. Podían delegar la compra o venta del vino propio, encargar a terceros vino para presentar ${ }^{33}$, o vender sus derechos de entrada a terceros, a cambio de que éstos paguen un dinero por el albarán ${ }^{34}$. Comprar cualquier vino de cualquier lugar para su consumo, o consumir vino de sus viñas situadas en señorío eclesiástico.

También tenian ventajas en el consumo y comercio de la carne: eran los únicos que podian vender tocino en la tabla del rey ${ }^{35}$; podian vender su buey, descuartizarlo en la carnicería los lunes y los miércoles, y venderlo a precio libre ${ }^{36}$; vender lomos de cerdo en adobo libremente ${ }^{37}$; matar reses, novillos $u$ otros ganados en las carnicerías del concejo ${ }^{38}$.

No era menor su prioridad en el aprovisionamiento: sobre los herreros para comprar hierro; sobre los intermediarios para comprar viandas y frutas; sobre carpinteros, albañiles, judío, moros, regatones para comprar madera para sus labores; sobre todos los demás habitantes e intermediarios en la compra de pescados de todo tipo, productos de consumo cotidiano y de cualquier apero de esparto e incluso de bestias para sus trabajos y transportes.

Pueden mandar hacer paños "para su vestir o para su compaña quier sea la natura del bervis o de otra manera qualquier que sea, jurando que no lo fazen para vender" ${ }^{39}$; cualquier tipo de cobertor, pellico o forro de cualquier tipo de piel mezclada o de peor calidad si es para sí o para su familia ${ }^{40}$; colchas para su casa $\sin$ guardar los controles de calidad fijados en las ordenanzas ${ }^{41}$.

Los vecinos tienen la potestad de realizar denuncias ante el concejo en todos aquellos casos en que se sientan perjudicados ellos o sus propiedades, por ejem-

\footnotetext{
O.T.4, capítulo III, folio VIIIv.

O.T.4, capítulo $V$, ley XI, folio XVIr.

O.T.4, capítulo $V$, leyes $V$ y VII, folios XIIIr y XVr

O.T.4, capítulo $V$, preámbulo, folio XIrr.

O.T.4, capítulo $V I$, ley $V I$, folio $X X I X V$.

O.T.4, capitulo $V i$, ley $V I I I$, folio $X X X V$.

O.T.4, capítulo $V$ I, ley $X I$, folio $X X X \| I$.

O.T.4, capítulo $V I$, ley $X V$, folio $X X X I I I V$

O.T.4, capítulo XXXVI, ley I, folio $L X I I I r$.

O.T.4, capítulo LI, ley I, folio Clr.

O.T.4, capitulo LII, ley VII, folio CIIIr.
} 
plo: a los criados que venden sus ganados sin su consentimiento ${ }^{42}$, a los revendedores de bestias que las venden muy caras ${ }^{43}$, a quien entre en sus propiedades sin permiso para pescar, cazar o cortar leña y retama ${ }^{44}$. Pueden emplazar ante el juez a cualquier habitante del término o a los criados de otros vecinos de Toledo que vivan en el término ${ }^{45}$. Los vecinos que fueren demandados ante el alcalde castellano, pueden pedir un cambio de jurisdicción y pasar a ser juzgados por el alcalde del Fuero Juzgo ${ }^{46}$.

\section{DEBERES DE VECINOS}

Intramuros, el espacio urbano se divide administrativamente en parroquias o colaciones. Este territorio se subdivide a su vez en barrios, y éstos en calles ${ }^{47}$. Todos los vecinos están asignados a una colación, de acuerdo con la zona de la ciudad donde viven. Este criterio topográfico conlleva la integración de los habitantes en una estructura político-administrativa distinta a los vinculos familiares que se mantienen en las sociedades agrarias ${ }^{48}$. Las colaciones eran el lugar idóneo para mantener la cohesión y solidaridad entre vecinos, dentro de un territorio menos extenso que la ciudad ${ }^{49}$. En ellas, los vecinos no solamente pagaban los diezmos eclesiásticos o acudian a celebrar acontecimientos y rituales religiosos, sino que eran el lugar más próximo de participación vecinal, celebrándose las reuniones periódicas para tratar los temas que les afectaban en razón de su residencia en el lugar y para elegir a los fieles. Estos eran los representantes de la colación encargados de vigilar que los acuerdos tomados se llevaran a cabo, que se cumplieran en su circunscripción los acuerdos municipales y las ordenanzas legisladas por el concejo, además de servir de interlocutores de los vecinos con el concejo.

Las funciones de los fieles de las colaciones, estipuladas en las en las ordenanzas, estaban relacionadas con el control social de a los vecinos en lo referente a la fiscalización de sus conductas, estando obligados a elaborar un censo de vecinos conflictivos, que no siguen un modo de vida "apropiado", e informar sobre ello al alcalde de la justicia. Además se encargan de reclutar a los vecinos peones

${ }^{42}$ O.T.4, capítulo $V I$, ley XVIII, folio XXXVV

${ }^{3}$ O.T.4, capítulo XVIII, folio LVV.

${ }^{44}$ O.T.4, capitulo XXXIX, folio LXXXIr y v.

45 O.T.4, capitulo XL, folio $L X X X \mid I I r$.

${ }^{6}$ O.T.4, capitulo LV, folio CXIIr.

47 En O.T.4, capítulo LXV, folio CXXXIIIV se ordena "a los vezinos e moradores en la collaçión e barrio o calle" que ayuden a la justicia a detener malhechores: $y$ en el capítulo LXVIII, folio CXXXVIV se manda que los fieles de las colaciones se informen "...las personas, asi varones como mugeres que moran e biven en cada barrio e calle de cada collaçión" que tengan mala fama para ponerlo en conocimiento de las autoridades.

${ }^{48}$ RUIZ DE LA PENA SOLAR, J. I.: "Las solidaridades vecinales en la corona de Castilla (siglos XII-XIV)". Cofradias. gremios, solidaridades en la Europa Medieval. Estella, XIX Semana de Estudios Medievales. 1992, pp. 30-113.

${ }^{49}$ Rucouol, A: "Valladolid del concejo a la comunidad". La ciudad hispánica durante los siglos XIII al XV. Madrid, Universidad Complutense, 1985, pp. 745-772. 
para organizar las guardias de las puertas, murallas y rondas, establecer las autodefensas civiles para capturar delincuentes y para formar parte de la milicia concejil.

Los habitantes de cada colación estaban obligados a contribuir a la limpieza de sus calles, ya que el concejo no daba este servicio a los ciudadanos. Tenían el deber de mantener la calle donde habitaban limpia de estiércol, basura, escombros, animales muertos y suciedad. Si no se podia responsabilizar a nadie en concreto de la suciedad, serían los cinco vecinos más próximos al lugar los que se tengan que hacer cargo de la limpieza y el traslado de las inmundicias al muladar extramuros $^{50}$. Todos ellos, igualmente, debian barrer y limpiar cada sábado sus calles y barrios "onde moran, cada uno su pertenençia» 51 . Debian igualmente arreglar las alcantarillas que se rompieran en su calle y cerrar cuanto antes las obras que se hicieran en ellas ${ }^{52}$; y desatascarlas cuando lo necesitaran ${ }^{53}$.

En cuanto a los deberes defensivos, se pueden agrupar en tres tipos: la vigilancia de la muralla, para que no entrara ninguna persona sin permiso, cosa que estaba penada con la muerte ${ }^{54}$, y para evitar la entrada y salida de mercancías sin conocimiento del concejo; la prevención del orden público y persecución de personajes delictivos; y la participación en el ejército del rey a través de la formación de la milicia concejil.

La vigilancia de la muralla estaba al cargo de los vecinos organizados por sus colaciones. Se patrullaba tanto noche como de dia. De noche se apostaban retenes en las zonas más vulnerables: puertas, portillos y huecos producidos por derrumbes de los lienzos. En todos ellos, se emplazaban peones reclutados en las parroquias más próximas, y se realizaban cinco rondas alrededor de todo el perímetro exterior de la muralla. Durante el día se vigilaban los dos puentes, y las puertas de Bisagra y del Cambrón ${ }^{55}$.

En cuanto a la protección ciudadana, los vecinos tenían la obligación de salir de sus casas con sus armas "a la boz e clamor de la justiçia» para ayudar a detener a los ladrones y malhechores ${ }^{56}$. También formar cuadrillas armadas para ayudar a la justicia a la captura de delincuentes. Para controlar preventivamente la delincuencia, el concejo acude de nuevo a los vecinos y a sus oficiales, los fieles de las colaciones, con el fin de que informaran de "quántas e quáles son las personas, asi varones como mugeres, que moran e biven en cada barrio e calle de cada collaçión, que non han buena fama, e en que aya alguna sospeçión porque non usen nin biven bien ni onestamente ni como deven..." 57 Una vez averiguado,

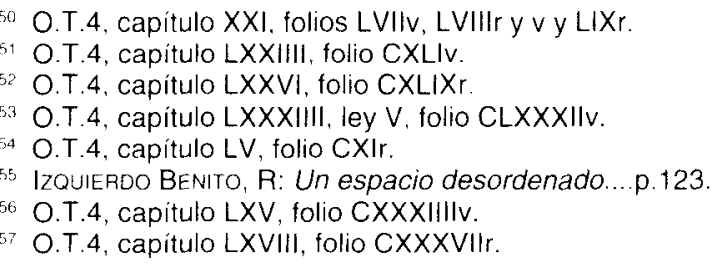


debian apuntar todas sus pesquisas "en sus quadernos" y entregarlo al alcalde de la justicia para proceder a la detención de los sospechosos.

La milicia concejil la formaban todos los vecinos de la ciudad: caballeros, escuderos y hombres buenos peones. No tenia pendón propio, ya que servian bajo las órdenes directas de los ejércitos reales. Este fue uno de los argumentos que esgrimió la ciudad de Burgos para poder tomar la palabra en primer lugar en las Cortes de Alcalá de Henares de 1348, a lo que Toledo replicaba que servían bajo el pendón real, "e non levaban pendón de concejo, pues lo non era: salvo cada rico ome, o caballero levaba su pendón e sus armas; ${ }^{58}$. De hecho Pedro I concede el 9 de noviembre de 1351 que las armas de Toledo sean las del rey.

\section{CONCLUSIONES}

La vecindad, en el Toledo bajomedieval, no es un estatus que comparten todos los habitantes intramuros, sino una condición privilegiada bastante restrictiva, al ser imprescindible para su detentación la propiedad de bienes inmuebles o raíces. Son vecinos, mayoritariamente, las capas más favorecidas de la población como los caballeros, clérigos, burgueses en tanto funcionarios y comerciantes, y artesanos. Sólo adquieren tal categoria una pequeña minoría de habitantes pertenecientes a las clases populares, y son excepciones puntuales los musulmanes admitidos en la vecindad, careciendo de ella totalmente los habitantes judíos. Los vecinos detentan todos los privilegios y derechos urbanos, tanto los concedidos por el rey, como por el propio concejo del que forman parte, que les proporcionan numerosas ventajas fiscales, comerciales, procesales, políticas y les dan acceso a cargos públicos, tendentes a conservar y acrecentar su patrimonio. Frente a ellos, la mayoria de los habitantes ciudadanos tiene la categoria de moradores. Éstos están obligados a acatar lo establecido en las ordenanzas municipales y no gozan de los privilegios de los vecinos.

Por tanto, la vecindad constituye una forma de discriminación de los habitantes intramuros, basada en criterios económicos de acceso a la propiedad, que conlleva el dominio de una minoria sobre la mayor parte de la población, desde el gobierno municipal. Todo ello sin prejuicio de que, dentro del vecindaje, existan diferencias sociales significativas que hagan recaer los puestos de responsabilidad en un grupo aún más reducido de caballeros, escuderos, dueñas, doncellas y hombre buenos que serán los que, a la postre, capitalizarán los beneficios del poder y el dominio y acabarán incluso patrimonializando los bienes municipales. 